\title{
Parametric Study of EWECS (Engineering Wood Encased Concrete- Steel) Columns Using 3D FE Modelling
}

\author{
Fauzan $^{\#}$, Ruddy Kurniawan", Zev Al Jauhari ${ }^{\#}$ \\ ${ }^{\#}$ Department of Civil Engineering, Andalas University, Limau Manis, Padang, 25163, Indonesia \\ E-mail:fauzanrn@yahoo.com,fauzan@ft.unand.ac.id
}

\begin{abstract}
This paper presents an analytical study on the behavior of composite column that consist of an exterior wood panel with concrete encased steel (CES) core, hereafter referred to as Engineering Wood Encased Concrete-Steel (EWECS) columns. A detailed three-dimensional (3D) nonlinear finite element model is developed to study the response and predict the seismic performance of EWECS columns subjected to both axial and cyclic loads by using finite element program, ANSYS APDL v.14. A reference model is validated with previous test results and is used as a reference for the parametric study. The parameters considered in the parametric study are the thickness of the wood panel and the compressive strength of concrete. The analytical results obtained from the finite element analysis can accurately simulate the behavior of the EWECS column on the experimental study. The results show that the EWECS column has excellent seismic performance. Moreover, the results of the parametric study show that the thickness of wood panel has the greatest influence on the seismic behavior of the EWECS columns, with the increment of flexural capacity of $15 \%$ by addition of $10 \mathrm{~mm}$ thickness of the wood panel. Meanwhile, the increase of concrete strength has not much influence on the flexural capacity of the EWECS columns, in which the flexural capacity of the EWECS column only increases around $3 \%$ with the increase of concrete strength from 35 to $60 \mathrm{MPa}$.
\end{abstract}

Keywords — EWECS column; finite element method; ANSYS; seismic behavior

\section{INTRODUCTION}

Building structure-using wood has been widely used in many countries, such as in Japan due to the friendly environment and culture. However, the wooden structure has been strictly limited in order not to have more than three stories based on the Building Standard Law of Japan [1]. To overcome this problem, a new hybrid structural system has been proposed [2], called engineering wood encased concrete-steel (EWECS) structural system, as shown in Fig. 1 .

In this structural system, the column consists of concrete encased steel (CES) core with the wood panel as a column cover, hereafter referred to as EWECS column. The use of a wood panel in the column has many advantages, not only economical but also structural benefits. The wood panel can be used directly as a formwork for the column during concrete placement, which reduces the construction cost. In the structural point of view, the wood panel act as core confinement and resistance to internal forces and buckling of the column. Therefore, the EWECS column is possible as an alternative to SRC columns, which have difficulty in constructing the steel section and reinforced concrete [2], [3].

An experimental study on the seismic performance of EWECS columns has been done in Japan [2]. The column has single H-section steel (Fig. 1), which is subjected to both constant axial and lateral cyclic loads. The performance of the column is examined regarding hysteresis characteristics, axial deformations, and failure patterns.
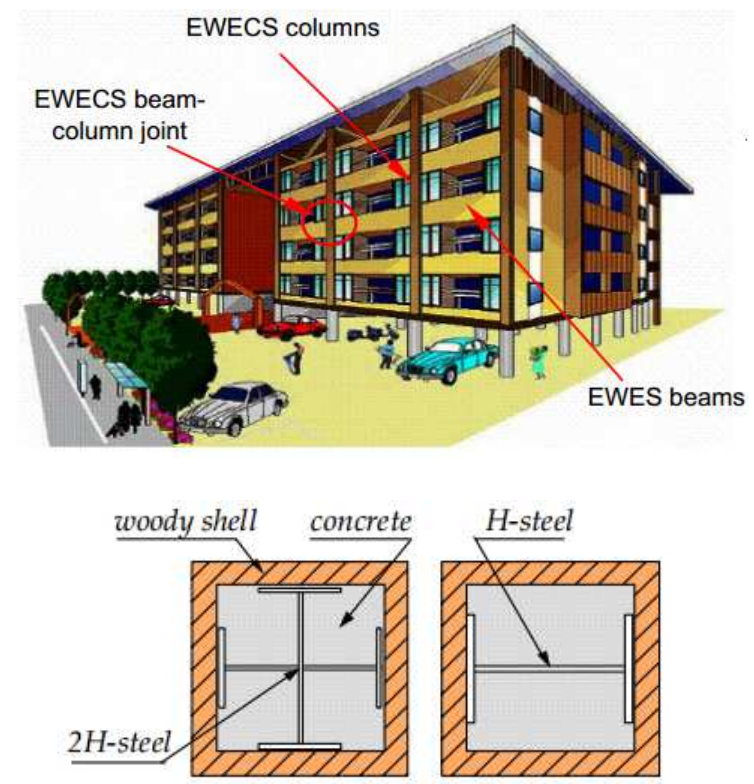

Fig. 1 EWECS structural system and cross section of EWECS columns [2] 
To validate the experimental results, a numerical study is carried out. The nonlinear finite element model is a powerful tool, and it can provide the researcher with much relevant information that cannot be supplied by the experimental test [4]. This study aims to develop a finite element (FE) model using ANSYS APDL 14.0 [5] to predict the seismic performance of EWECS column subjected to both constant axial and lateral cyclic loads.

ANSYS is capable of handling dedicated numerical models for the behavior of concrete under static and dynamic loading [6]. This software has proven its reliability in many benchmark studies and is considered suitable for the current task. The developed model is considering the nonlinear behavior of the material. The results of the numerical model are compared with the test results. Furthermore, a parametric study is performed with parameters of wood panel thickness and concrete compressive strength.

\section{MATERIAL AND METHOD}

\section{A. The Geometry of 3D FE Model}

Details of the experimental program regarding the geometry of steel section, concrete, and wood panel are described in Fig. 2. The specimen had $1600 \mathrm{~mm}$ height and $400 \mathrm{~mm}^{2}$ section area. A wood panel covers the specimen with a $45 \mathrm{~mm}$ thickness, while the core section is concrete encased steel. Steel encased in the column had a cross shape section $\mathrm{H}$-section of $300.220 .10 .15 \mathrm{~mm}$. The dimensions and geometrical configuration of the test specimen are used to construct the FE model. Concrete, steel, and wood panel are modeled as a block and solid cube with an equivalent length representing the total area of the specimen. The mesh density is chosen so that the element aspect ratio is nearly equal to one. This provides adequate accuracy and fair computational time in modeling the EWECS column. The total numbers of element used are 5095 elements.

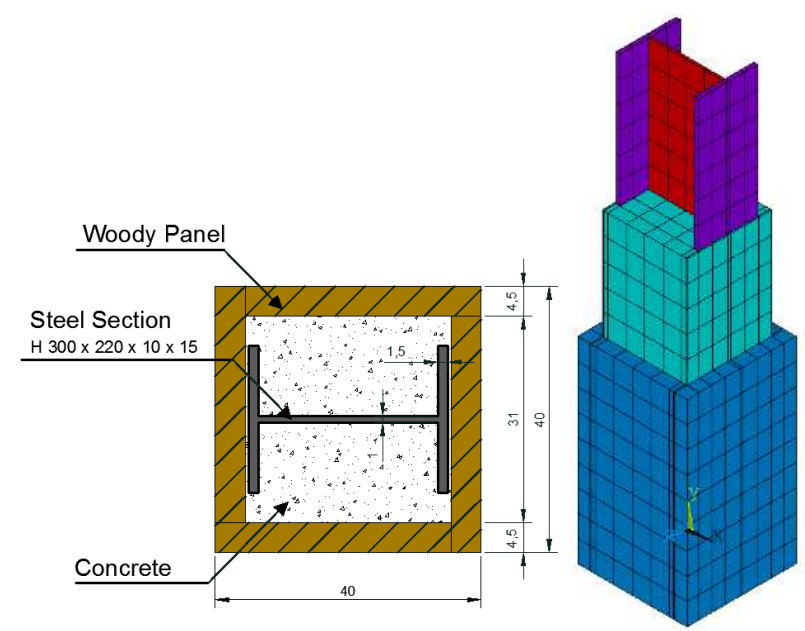

Fig. 2 Detail of test specimen and 3D model view of EWECS column

\section{B. Material Properties}

1) Concrete: The compressive strength of the concrete used in the model is $35 \mathrm{MPa}$. A peak concrete strain of 0.0025 is used in the analysis. Fig. 3 presents the compressive stress-strain curve for the concrete. The stress- strain relationship is designed on the FE model developed by Saenz [7]. The tensile relaxation is characterized by a sudden reduction of the tensile strength to $0.6 \mathrm{x} \mathrm{f}_{\mathrm{r}}$ after reaching the tensile cracking strain $\varepsilon_{\mathrm{cr}}$. After this point, the tensile decreases linearly to zero stress at a strain of $6 \times \varepsilon_{\mathrm{cr}}$, as shown in Fig. 4. Additional concrete material data, such as the shear transfer coefficient for open cracks $\left(\beta_{t}\right)$ and closed cracks $\left(\beta_{c}\right)$ are needed for the concrete constitutive material data. A shear transfer coefficient suggested by Al-Mahaidi [8] is included in the analysis, with a value of 0.75 and 0.9 for $\beta_{\mathrm{t}}$ and $\beta_{\mathrm{c}}$, respectively. Five-parameter model of WilliamWarnke is applied as the fracture criterion in the concrete model [9].

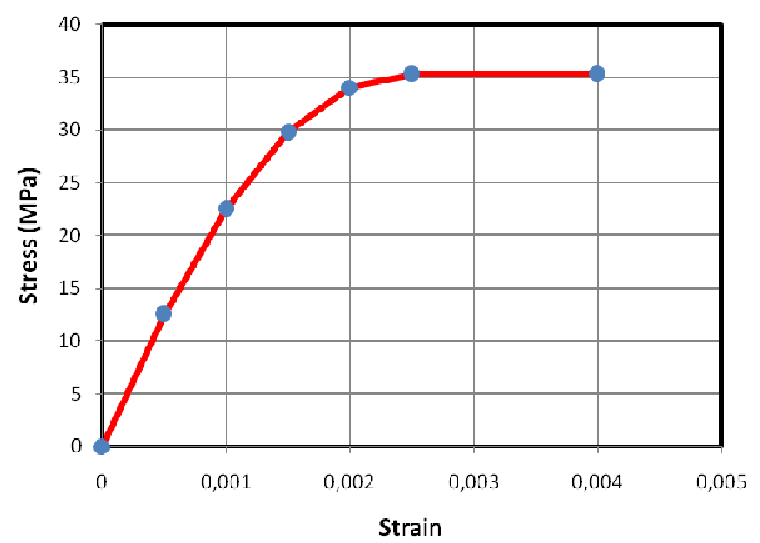

Fig. 3 The idealized compressive stress-strain curve for concrete

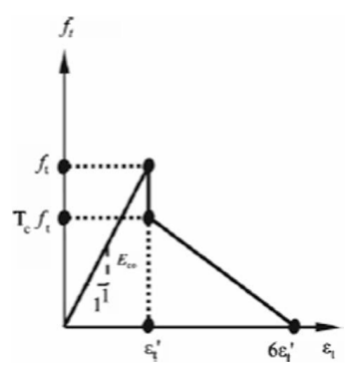

Fig. 4 Idealized tensile stress-strain curve for concrete [7]

2) Encased Steel: The yield strength of the encased steel used in the FE model is 293.6 and $313.3 \mathrm{MPa}$ for flange and web, respectively.

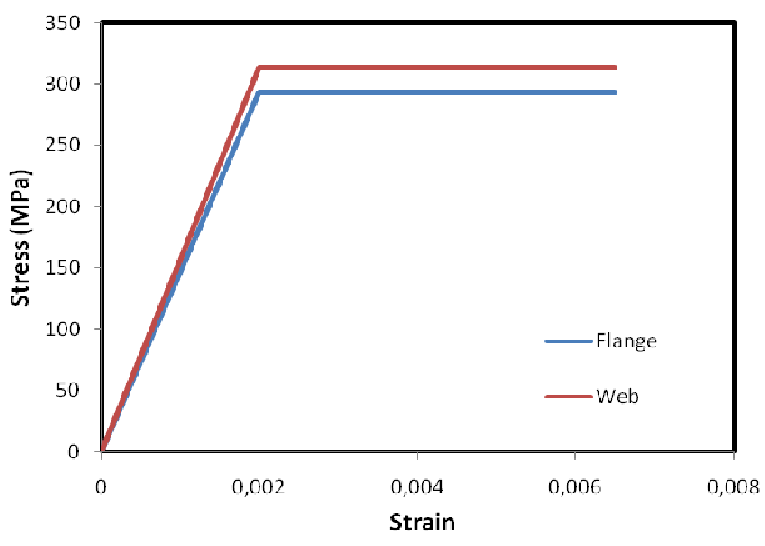

Fig. 5 Stress-strain relationships for steel

The constitutive model of the encased steel used in this study is a perfectly elastic-plastic criterion, as shown in Fig. 
5. At first, this curve is elastic; then it is assumed to be perfectly plastic (bilinear isotropic model). This curve is suitable for representing stress-strain characteristics of normal and high-quality steel section. Von Mises yield criterion is applied in a constitutive model of the steel.

3) Wood Panel: The compressive strength and modulus elasticity of the wood panel are $46.2 \mathrm{MPa}$ and $13700 \mathrm{MPa}$, respectively. Some existing concrete models built in the program by many researchers might be used in the analysis with some modifications because the design to allow the force to be applied in the parallel direction to the annual growth ring of the wood [10]. The stress-strain relationship is modeled with the linearly increasing model with slightly reduced (5\%), as shown in Fig. 6.

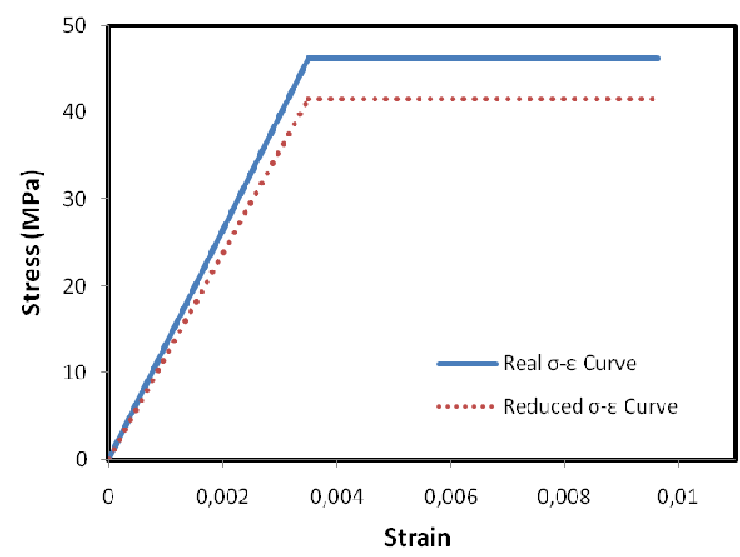

Fig. 6 Stress-strain relationships for wood panel

In this FE analysis, the maximum tensile strength of the wood is taken as $5 \mathrm{MPa}$ due to the unbonded connection between concrete and wood panel, and also it considers the lower tensile strength in the direction perpendicular to the wood grain. The shear transfer model for concrete developed by Al-Mahaidi [8] is included with the modified shear transfer coefficient $\beta_{\mathrm{c}}$ of 0.35 for wood. The fracture criterion of wood is adopted by following the rule of the five-parameter model of William-Warnke [9] for concrete with the input of wood material characteristics.

\section{Element Type}

There are two types of elements used to model the materials in the EWECS Column. ANSYS SOLID185 is used in this model to steel and wood, while SOLID65 to the concrete one. These elements are a 3D hexahedral element defined by eight nodes, which have three translational DOF at each node in the nodal $\mathrm{x}, \mathrm{y}$, and $\mathrm{z}$ directions, as shown in Fig. 7. The SOLID185 element has the capability of plastic deformation, hyperelasticity, stress stiffening, creep, large deflection and strain. The element also has mixed nonlinear formulation that can be used for simulating deformations of incompressible elastic-plastic materials. The SOLID65 element has the capability of plastic deformation, creep, cracking in three orthogonal directions, and crushing in compression. This element also has a treatment for nonlinear material properties [5].

The FE model in this study is considered perfectly bonded for the material interface between steel and concrete [11], while unbonded for the material interface between wood and concrete is performed by slightly reducing the constitutive model of wood panel. This assumption is applied because, in the previous experimental results (the comparison of seismic behavior between EWECS column with and without shear studs), bonded and unbonded between adjacent materials (wood and concrete) are not much influenced for flexural capacities of the columns [12].
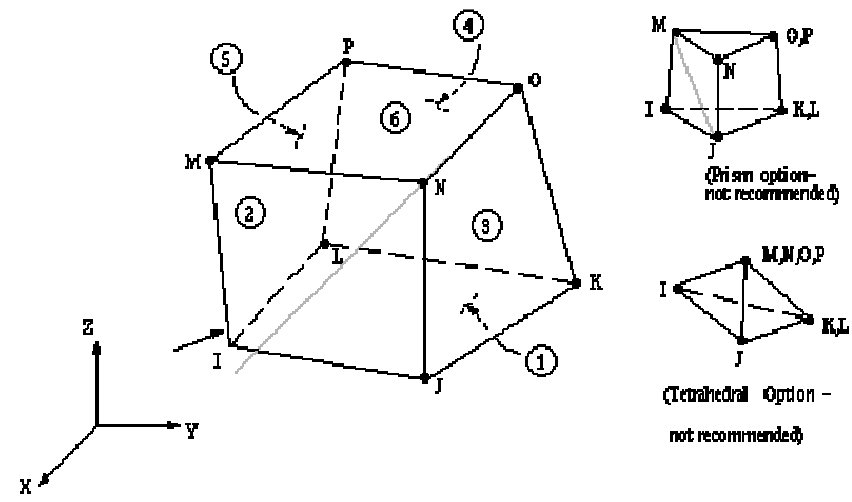

Fig. 7 Solid65 and Solid185 ANSYS elements [5]

\section{Boundary Conditions}

The boundary conditions are made to consider the test setup, as seen in Fig. 8. An anchor plate/ stub (700.700.400 $\mathrm{mm}$ ) is used in the model at the top and bottom of the column. The final boundary conditions of the FE model are shown in Fig. 9. Nodes at the bottom edge of the column are restrained in all translational DOF, and top of the column are restrained in the vertical y-direction. The nodes at the two edge lines of the stub column are coupled in the horizontal direction to ensure all the nodes associated with this line move together.

E. Loads

The loads are applied to the FE Model as follows:

- Constant axial load, approximately $1031 \mathrm{kN}$, is applied to the top stub of the column. This is represented in the FE model by applying a point pressure of $1.4 \mathrm{kN}$ on the stub elements with a total nodal of 717 .

- The lateral cyclic load is represented in the FE model by applying the displacement at the top edge of the stub column. Story drift controls the increments of lateral loading cycles, $\mathrm{R}$, defined as the ratio of lateral displacement to the column height, $\delta / \mathrm{h}$. The lateral load consists of one cycle to each $\mathrm{R}$ of $0.5,1,1.5,2,3$, $4 \%$ and followed by half cycle to R of $5 \%$, as shown in Fig. 10.

\section{F. Nonlinear Solution}

The applied cyclic displacements are divided into a series of increments called load steps and load substeps. The automatic time stepping option is enabled in this analysis to predict and control the load step size increments. NewtonRaphson equilibrium iterations are updated the model stiffness in ANSYS [13]. In this study, the convergence criteria for the elements are based on displacement. ANSYS convergence tolerance default values of 5\% for displacement 
checking are initially selected. It is found that convergence is difficult to achieve using the default values due to the associated large deflections and the highly nonlinear behavior of the concrete elements. Thus, in order to obtain convergence of the equilibrium iterations, the convergence tolerance limits are increased to $10 \%$ for the displacementchecking criterion.

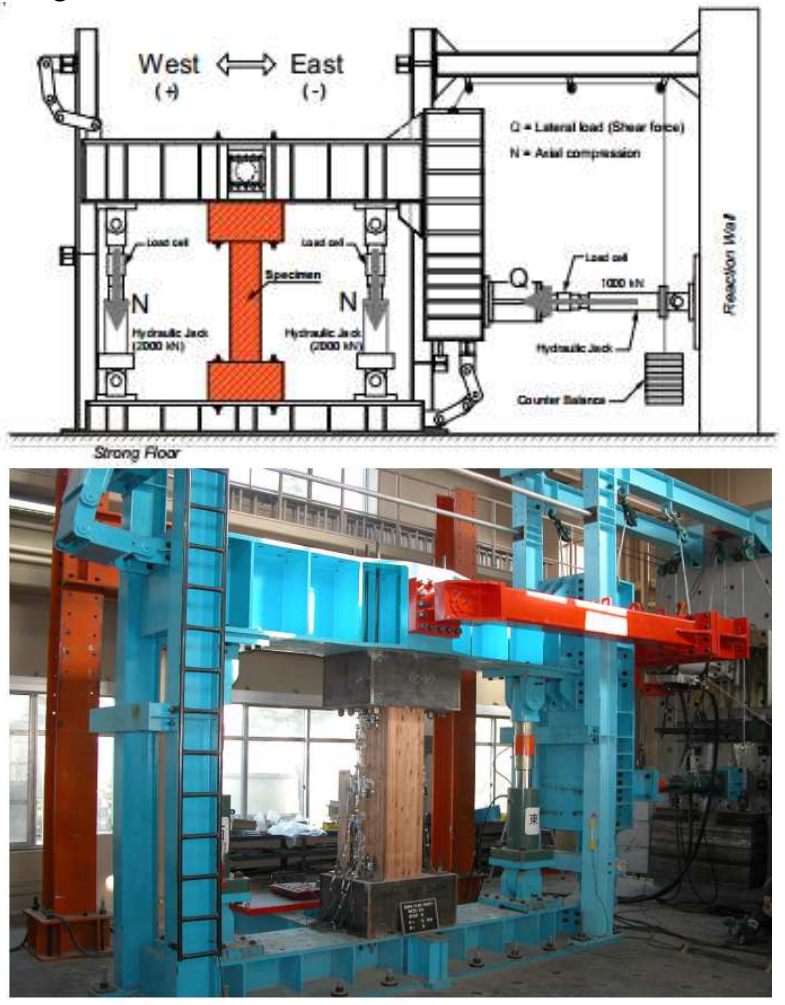

Fig. 8 Schematic view and photo of the test setup

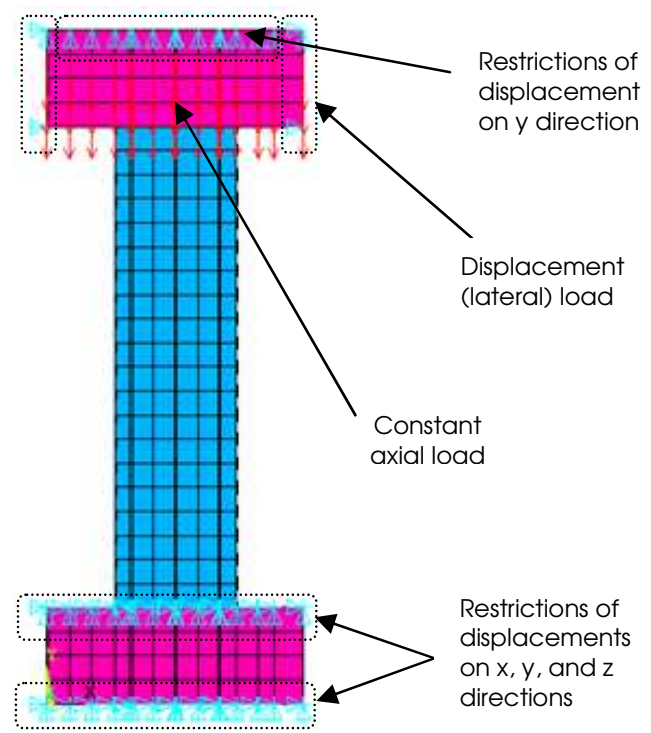

Fig. 9 Boundary conditions and loads in the FE model

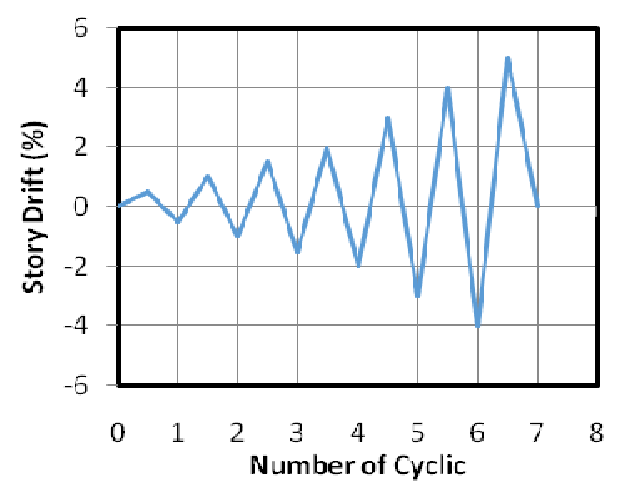

Fig. 10 Lateral cyclic loads

\section{RESULTS AND DISCUSSION}

\section{A. Validation of Proposed Model}

1) Hysteresis Characteristics: The experimental hysteresis loop (shear force vs. story drift) for the EWECS column is compared to those obtained from the numerical analysis, as shown in Fig. 11. The maximum shear force for the FE model is $778 \mathrm{kN}$ obtained at $\mathrm{R}$ of $5 \%$. This is approximately $6.8 \%$ higher than the results obtained from the experimental $(725 \mathrm{kN})$. It is clear from the figure that the FE and test results are almost the same in each stage of cyclic loading. The different percentage of lateral shear force in each stage of loading cycles from the FE analysis and the experimental results is around $2-8 \%$.

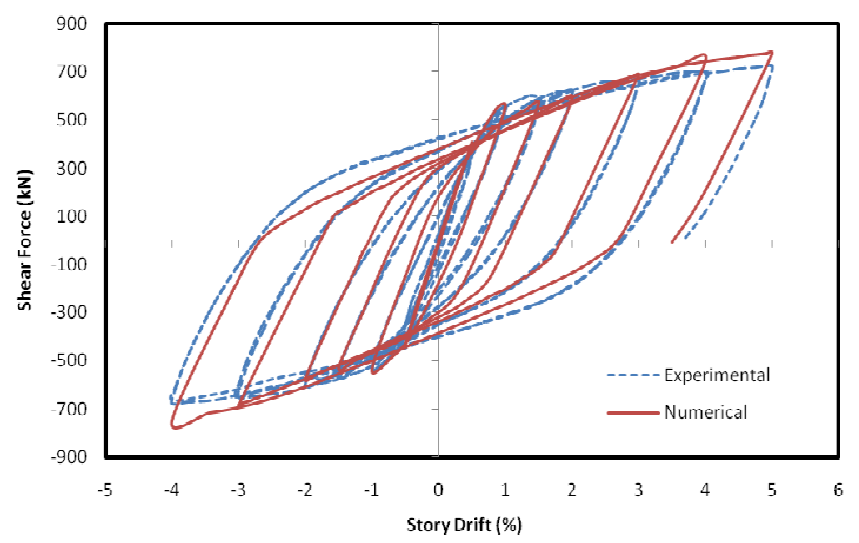

Fig. 11 Comparison of the hysteresis loop of EWECS column between test and numerical results

2) Axial Deformation: Fig. 12 shows the comparison of the longitudinal elongation versus story drift for the test specimen and the FE model. The red and blue solid lines represent the history of deformation for the FE model and test specimen respectively. As shown in the figure, the slope of incremental elongation of the test specimen for each cycle is slightly higher than that of the FE model. It is found that the maximum deformation of $2.62 \mathrm{~mm}$ at $\mathrm{R}$ of $5 \%$ is observed for the test specimen, while the maximum deformation in the FE model is $3.34 \mathrm{~mm}$ at $\mathrm{R}$ of $5 \%$. 


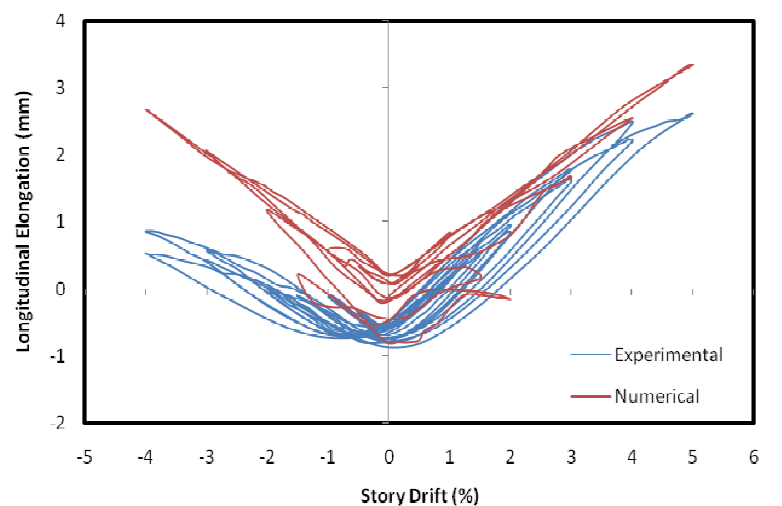

Fig. 12 Comparison of axial deformation of EWECS columns between test and numerical results

3) Failure Mode and Principal Stress Distribution: In the previous experimental study, the brittle failure of the wood and severe damage of the column are observed significantly after $\mathrm{R}$ of $3 \%$. By removing the wood panel after testing, it is observed that the infill concrete has crushed at both top and bottom of the column in flexure and no local buckling occurred at the encased steel. This failure mechanism is also observed in the FE model. Figs. 13 and 14 present the comparison of failure patterns between the test specimen and numerical model.

The stress in the each of material is also analyzed to validate the FE model. A major strain of 0.002 has been reached in the encased steel of EWECS model at story drift $0.51 \%$, as indicated that the steel has first yielded in red in the Fig. 15 (a). The elastic modulus of the steel is 156700 $\mathrm{MPa}$, with corresponding stress equal to the yield stress 324 $\mathrm{MPa}$. On the other hand, the first yield in the corner region both of the top and bottom of the steel during experimental is at $\mathrm{R} 0.57 \%$. The minimum principal stress distribution in the FE model illustrates that first crack in the concrete starts at $\mathrm{R}$ of $0.3 \%$ in the strut zone, and propagate to the horizontal direction, as seen in Fig. 15 (b).
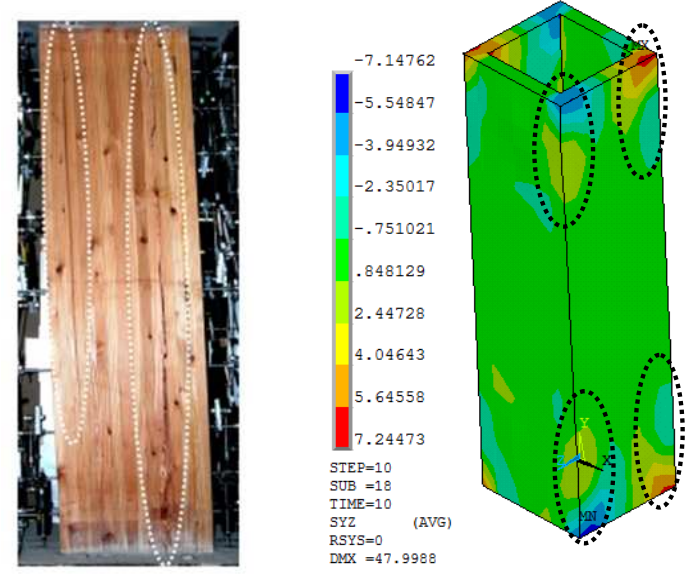

Fig. 13 Failure patterns in wood panel

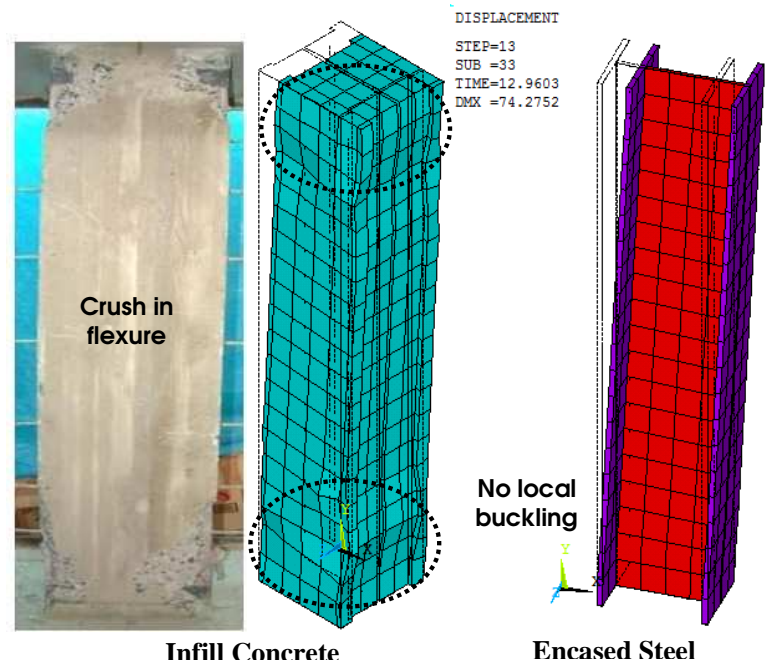

Fig. 14 Failure patterns in infill concrete and encased steel

The principal shear stress in the wood panel, as shown inside the oval shape in Fig. 13, shows that the crack occurred in the location where the wood panels are assembled by using wood glue at a shear stress of approximately 7.24 $\mathrm{MPa}$ (maximum principal shear stress). This corresponds to the tangential shear strength of normal wood suggested by Calderoni [14] is averaged at 7.44 MPa. The crack occurs in this location; it might be attributable to the weak shear strength of the connection using wood glue during construction of the specimen. Cracks are also formed at the opposite side. They propagate along the column height. These results indicated that the FE model satisfactory portrays the behavior of the column.

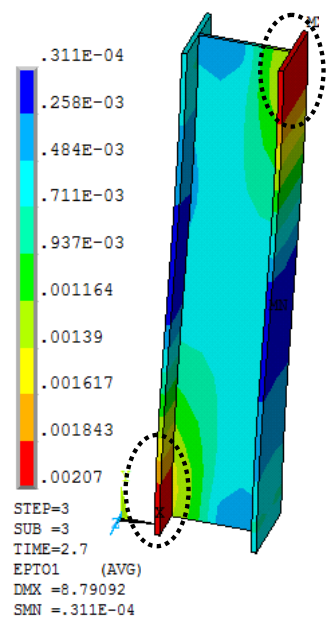

(a)

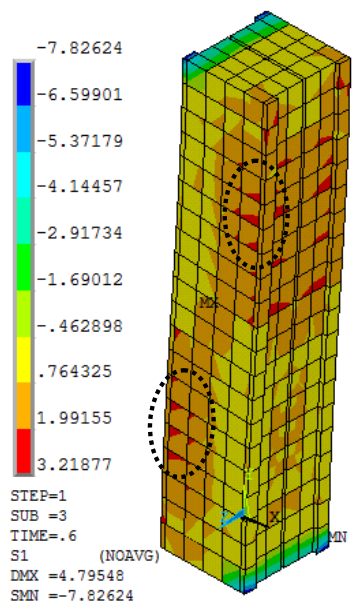

(b)
Fig. 15 (a) First yield in the steel web and (b) first crack in the concrete

\section{B. Parametric Study of EWECS Column}

From the above numerical analysis of EWECS column, the FE model can provide an accurate prediction for its seismic behavior, which has been compared to the experimental program. A parametric study is performed to deeply understand the EWECS column behavior and identify a possible material that has more significant influence on the column. The parameters studied are wood panel thickness and concrete compressive strength. These parameters are 
chosen because of the importance of the material in structural resistance, and it can improve seismic behavior without significantly changing the column dimensions. There are three different values used in each parameter, as shown in Table 1. The numerical model, which is validated with the test results, is called the reference model (Model R) in the parametric study [15].

TABLE I

PARAMETER VAlues Selected For Parametric Study

\begin{tabular}{|c|c|}
\hline Parametric & Value \\
\hline Thickness of wood & $35 \mathrm{~mm}, 45 \mathrm{~mm}(\mathrm{R}), 55 \mathrm{~mm}$ \\
\hline Comp. strength of concrete & $35 \mathrm{MPa}(\mathrm{R}), 50 \mathrm{MPa}, 60 \mathrm{MPa}$ \\
\hline
\end{tabular}

1) The thickness of the Wood Panel: Wood panel is a column component that provides the core confinement and resistance to bending moment, shear force and column buckling. The thickness of the wood panel is varied to evaluate the influence of this parameter on the column behavior. The thickness used in the parametric analysis is determined by the commonly used thickness of the wood panel ranges from $40-60 \mathrm{~mm}$. The material properties of the wood, such as the compressive strength, elastic modulus, and other coefficients, are the same as those in the reference model. Fig. 16 presents the shear force versus story drift (hysteresis loop) of EWECS columns with having variation in the thickness of the wood panel. These curves illustrate the differences between the stiffness, strength, and energy dissipation of each model, as listed in Table 2.

The model with wood panel thickness of $55 \mathrm{~mm}$ (Model B) displays a stiffness of $13 \%$ higher than the reference model (Model R), whereas the model with wood panel thickness of $35 \mathrm{~mm}$ (Model A) displays a 14\% smaller than Model R. The addition of $10 \mathrm{~mm}$ thick of wood panel can increase the flexural capacity by around $15 \%$. A thicker of the wood panel lead to a higher energy dissipation of around $6-10 \%$. The results of simulations indicate that the thickness of wood panel has a significant influence on the seismic behavior of the column.

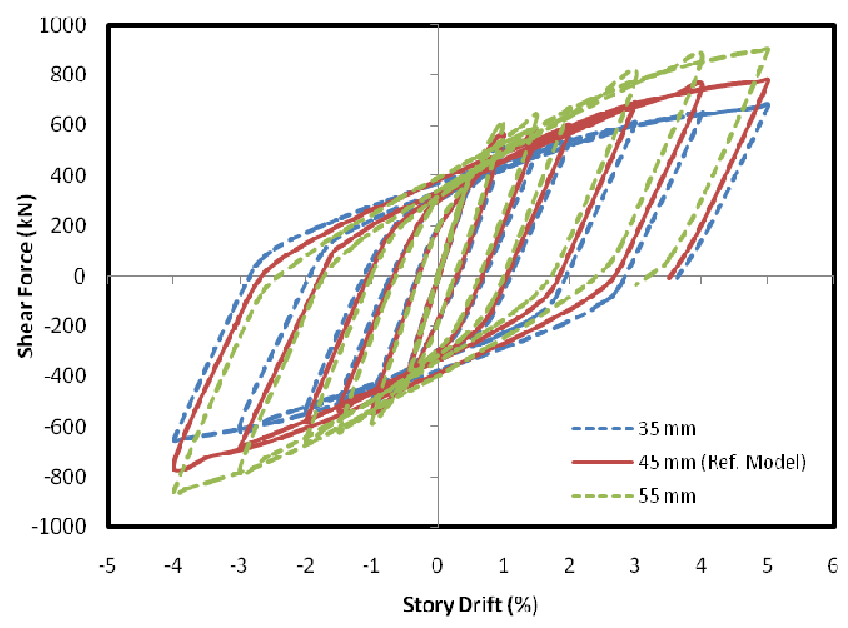

Fig. 16 Comparison of the hysteresis loop of EWECS columns with varying the thickness of the wood panel
TABLE II

RESULTS OF PARAMETRIC STUDY OF EWECS COLUMNS WITH VARYING THE THICKNESS OF WOOD PANEL

\begin{tabular}{|c|c|c|c|}
\hline Model & $\begin{array}{c}\text { Max. Strength } \\
(\mathbf{k N})\end{array}$ & $\begin{array}{c}\text { Stiffness } \\
(\mathbf{k N / m m})\end{array}$ & $\begin{array}{c}\text { Energy } \\
\text { Diss. }(\mathbf{k J})\end{array}$ \\
\hline $\mathrm{A}(35 \mathrm{~mm})$ & 678.1 & 9.23 & 194.0 \\
\hline $\mathrm{R}(45 \mathrm{~mm})$ & 778.4 & 10.61 & 214.6 \\
\hline $\mathrm{B}(55 \mathrm{~mm})$ & 900.3 & 12.23 & 228.8 \\
\hline
\end{tabular}

2) Compressive Strength of Concrete: The concrete compressive strength used in this parametric study is based on the comparison of the seismic behavior of EWECS columns between those using standard and high strength concrete. The features of other structural elements in numerical simulations of parametric analysis remain constant. The related data for parametric analysis is similar to reference model analysis. Fig. 17 and Table 3 show the comparison of hysteresis loops and seismic performance (stiffness, strength, and energy dissipation) of EWECS columns with respectively having variation the compressive strength of concrete.

The model with concrete compressive strength of 50 MPa (Model C) displays a stiffness of $9 \%$ higher than the reference model (Model R), whereas the model with concrete compressive strength of $60 \mathrm{MPa}$ (Model D) displays a $2.71 \%$ greater than Model R. A higher compressive strength of concrete lead to a higher energy dissipation around $8-12 \%$. Model C displays a $3.4 \%$ increase in maximum flexural capacity, while Model D displays a $3.7 \%$ increase in maximum flexural capacity to resist the lateral load. These results indicate that the increase of concrete compressive strength does not much influence on the maximum flexural capacity of the EWECS column.

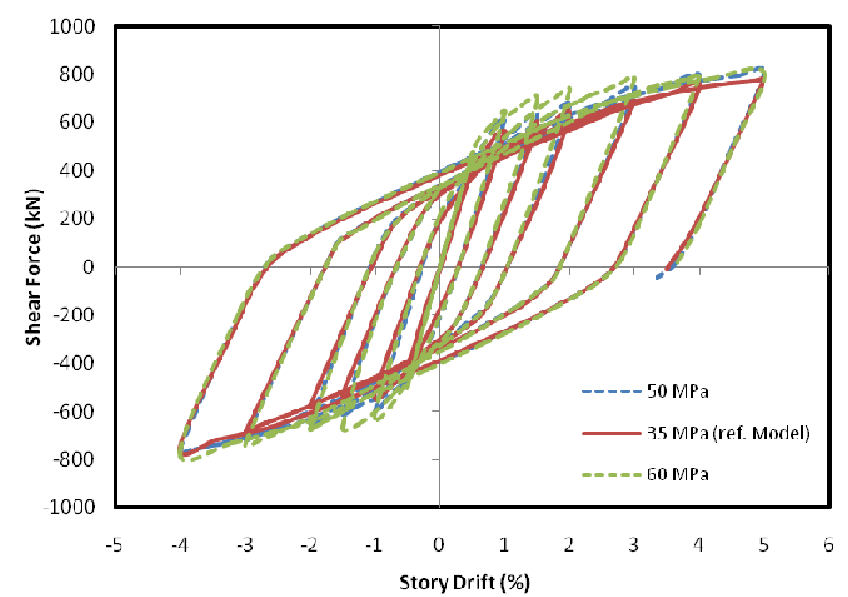

Fig. 17 Comparison of the hysteresis loop of EWECS columns with varying the compressive strength of concrete

TABLE III

RESUlTS OF PARAMETRIC STUDY OF EWECS COLUMNS WITH VARYING THE COMPRESSIVE STRENGTH OF CONCRETE

\begin{tabular}{|c|c|c|c|}
\hline Model & $\begin{array}{c}\text { Max. Strength } \\
(\mathbf{k N})\end{array}$ & $\begin{array}{c}\text { Stiffness } \\
(\mathbf{k N / m m})\end{array}$ & $\begin{array}{c}\text { Energy } \\
\text { Diss. (kJ) }\end{array}$ \\
\hline $\mathrm{R}(35 \mathrm{MPa})$ & 778.4 & 10.61 & 214.6 \\
\hline $\mathrm{C}(50 \mathrm{MPa})$ & 804.9 & 10.98 & 232.3 \\
\hline $\mathrm{D}(60 \mathrm{MPa})$ & 807.3 & 10.95 & 240.3 \\
\hline
\end{tabular}




\section{CONCLUSION}

In general, the hysteresis loop, axial deformation, and failure mode of the FE model of EWECS column satisfactory portray the behavior of the test column both in elastic and plastic ranges. The FE model has a stable spindle-shape hysteresis characteristic by having little damage on the column even at a final story drift. A good correlation exists in all stages of cycling loading. Individually, the FE results for the peak loads are slightly higher than the test results (within 2-8\%) in each stage of cyclic loading.

The results of the parametric analysis demonstrate that the most significant influence parameter on the seismic behavior of EWECS columns is the thickness of the wood panel, in which the addition of $10 \mathrm{~mm}$ thick of wood panel increases the flexural capacity around $15 \%$. Meanwhile, the increase of concrete strength does not much influence on the flexural capacity of the EWECS columns. The flexural capacity of the EWECS column only increases around 3\% with the increase of concrete strength from 35 to $60 \mathrm{MPa}$.

\section{REFERENCES}

[1] Ministry of Construction, Stipulation of criteria with respect to structural calculations performed to confirm the safety from the point of view of the structural capacity of wooden columns. Building Standard Law of Japan Notification No. 1349, May 23, 2000.

[2] Fauzan, H. Kuramoto, and K.H. Kim, "Seismic performance of composite EWECS columns using single H-steel," Proceeding of JCI 27(2), 2005, pp. 307-312.

[3] H. Kuramoto, and Fauzan, "Feasibility study on engineering wood encased concrete-steel composite columns," Proceeding $11^{\text {th }}$ Int. Colloquium on Structural and Geotechnical Engineering $\left(11^{\text {th }}\right.$ ICSGE), Ain Shams University, Cairo, Egypt, 2005.
[4] M. M. A. Kadhim, "Nonlinear FE analysis of reinforced H.S concrete continuous beam strengthened with CFRP sheet,' Proceeding of the International Conference on Advanced Science, Engineering and Information Technology, 2011, pp. 597 - 601.

[5] ANSYS Version 14. 2010. Users and theory reference manual.

[6] M. K. Hassan, M. F. M. Zain, and M. Jamil, "Finite element analysis of the effect of crack depth and crack opening on the girder," Proceeding of the International Conference on Advanced Science, Engineering and Information Technology, 2011, pp. 646 - 651.

[7] L. P. Saenz, "Discussion of the equation for the stress-strain curve for concrete" Journal of American Concrete Institute, vol. 61(9), pp. 1229-1235, 1964.

[8] R. S. H. Al-Mahaidi, "Nonlinear finite element analysis of reinforced concrete deep members," Rep. No. 79(1), Department of Structural Engineering, Cornell University, Ithaca, New York. 1979.

[9] K. L. Willam, and E. P. Warnke, "Constitutive model for the triaxial behavior of concrete," Proc. International Association for Bridge and Structural Engineering (IABSE), vol. 19, Zurich, Switzerland, 1975.

[10] H. Kuramoto, B. Li, K. Meas, and Fauzan, "Experimental and analytical performance evaluation of engineering wood encased concrete-steel beam-column joints," Journal of Structural Engineering ASCE, pp. 822-833, 2011.

[11] A. Leskes, and S. Grambicka, "Theoretical and experimental studies on composite steel-concrete columns," Proc. Eng. Science Direct, vol. 65, 2013, pp. 405-410.

[12] Fauzan, and H. Kuramoto, "Seismic performance of EWECS composite columns in the new hybrid structural system," Composite Construction in Steel and Concrete, vol. 6, pp. 263-275, 2011.

[13] R. A. Hawileh, A. Rahman, and H. Tabatabai, "Nonlinear finite element analysis and modeling of a precast hybrid beam-column connection subjected to cyclic loads," Journal of Applied Mathematical Modelling, vol. 34, pp. 2562-2583, 2010.

[14] C. Calderoni, G. D. Matteis, C. Giubileo, and F. M. Mazolani, "Flexural and shear behavior of ancient wood beams: an experimental and theoretical evaluation," Journal of Structural Engineering, vol. 28(5), pp. 729-744, 2006.

[15] N. Marcela, and L. Ana, "Parametric study of composite beamcolumn connections using 3D finite element modeling", Journal of Construction Steel Research, vol. 102, pp. 136-149, 2014. 